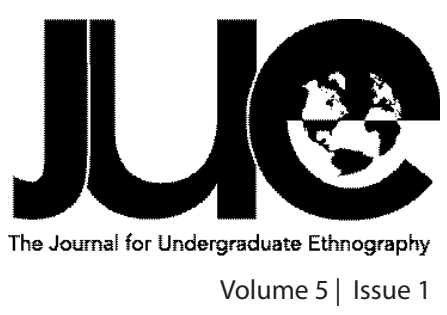

\title{
The Phenomenon of Naming: Maintaining and Defining Relationships
}

\author{
Claire Williamson \\ Saint Louis University—Madrid Campus, cwill129@slu.edu
}

\section{ABSTRACT}

his study of terms of address focuses on the use of naming in interpersonal conversation. Many individuals in the speech community of this American university in Spain use naming to refer to each other in interpersonal communication. Methods used to gather data on this practice were participant observation and informal interviews under the framework of ethnography of communication. It was found that participants used naming in order to get attention with emphasis, accentuate a joke, and bring the other interlocutor closer physically and relationally. These results imply that participants increase and maintain solidarity and intimacy relationally specifically through the use of naming.

Keywords: Terms of Address, Naming, Solidarity, Ethnography of Communication 
What do you call someone when you are speaking to him or her? Do you use their name in conversation? People use names, often unconsciously, when interacting with others. This use is not necessary in its most literal sense, that is, as deictics that function to indicate who is being addressed. So, why do people name other people when it is not apparently necessary? Naming, as studied here, is defined as a term of address characterized by the use of the addressee's personal name. Naming is limited to personal names, not special nicknames or second-person pronouns. For example, take the use of a name in the middle of a conversation between participants A and B. After explaining a concept, A concludes, "So do you understand what I mean, B?" even though the duration of the conversation has been conducted exclusively between the two participants. Much research has been conducted in recent years on the meanings behind different terms of address, but in those cases, naming is usually grouped with "additional terms" while the main focus is placed on other specific terms of address. Naming is an integral speech act in interpersonal communication that is often overlooked by society and researchers because it is only thought about in terms of its literal function: to address someone. However, upon studying naming in a wider range of contexts, it becomes clear that it is a much more nuanced practice that goes beyond its literal function as a term of address, which calls for further exploration into its meanings and usages. This approach will grant us a vantage point to better understand identity and social relations.

\section{LITERATURE REVIEW}

Studies of naming exclusively as a term of address are scarce. The majority of studies focus on second-person pronoun address terms such as informal versus formal address, and subsequent power dynamics and other social structural developments in various languages (Winchatz 2001, 339, 362). This study of power dynamics can be broken down into investigating the use of honorifics or titles to indicate status versus the use of nicknames or first names to indicate solidarity or lower status (Takiff et al. 2001, 134, Weizman 2008, 117).

Other studies look at address terms that are based on colloquialisms such as Kiesling's $(2004,281)$ study of the use of "dude" and Rendle-Short's $(2009,3)$ analysis of the Australian term "mate." Both studies focused on the social construction of gendered identity, especially masculinity, through such terms. Studies of the construction of femininity through terms of address are less common, however Villanueva's (1995, 10-15) research on gendered naming in Mexico reflects how femininity is constructed in that speech community through terms of address. Terms of address, specifically the adapted use of names, were also studied as derogatory labels or as face-threatening acts by Aghbari $(2010,345)$ in Omani Arabic, a practice exclusively used by the women in that society, and by Weizman $(2008,116)$ in her study of role relationships in news interviews.

Catrin Norrby and Jane Warren's $(2012,229)$ investigation of the term of address choice in French, German, and Swedish groups took a more social constructionist standpoint than other research. They asserted that terms of address function as indicators of social relationships and can be used to understand social structure and cultural values within specific speech communities. Their study took Brown and Gilman's (1960) model explaining second-person pronoun choice (referenced in Norrby and Warren 2012, 226), and asserted that cross-cultural languages and second-language learning processes are two key factors in address choice that need to be taken into consideration along with power and solidarity. In this study on naming, social motives other than ones centered on identity were uncovered, so Norrby and Warren's study, from a social constructionist standpoint, informs the analysis of this research nicely.

This body of research informed my current investigation, and it evidenced a thematic gap: the academic community hasn't studied naming exclusively, nor what it means, in detail yet. My 
research intends to begin to fill said gap. Studying naming is critical because although it is useful to investigate identity construction, it also is capable of opening a window to richer understanding of social relationship structure as enacted through communication. The research questions that structured my investigation were: How is naming used to construct meaning? What is the meaning that is constructed through naming in interpersonal interactions?

\section{METHODS}

The principal method of data collection was ethnographic participant observation. I participated in interactions with other members of the speech community as a play participant, identified as an active participant in a speech community who also performs the function of an observer, and as a focused participant observer, which is distinguished as an individual who places importance on acting and thinking as an observer before participant. These roles are further outlined by Tracy $(2013,109$ 113). Both were taken on because in the first case, I was already an established member of the speech community and in order to gather data, I had to join in activities that allowed for naming to take place, but in the second case, I also always had an ear to the ground for instances of naming in interactions with friends and acquaintances and occasionally asked probing questions regarding name choice in the moment. In this way, I participated in normal activities pertaining to the speech community, and was able to record instances of naming that occurred within the everyday context.

Over the course of two and a half months, I observed five specific communication scenarios and I recorded several naming instances in each case. I also held three open-ended interviews, as described by Tracy (2013, 160-162), with members of different cultural backgrounds in order to obtain a better understanding of participants' meanings and interpretations of the phenomenon of naming. Throughout the process I obtained consent from the participants to be observed and quoted. The speech community consisted of college students from a variety of cultural backgrounds attending an American university in Spain and predominantly communicating with each other in English. I studied several distinct social groups within this broad community to uncover whether certain uses of naming were limited to specific individuals or circumstances. Since the speech community was limited to university students, communication scenarios took place on campus during free time or off campus at informal student gatherings, and therefore were between friends and classmates. The multilingual nature of the participants has to be taken into consideration when discussing the meanings of naming since different cultural backgrounds and practices inform choices of term of address.

\section{ANALYTIC PROCEDURES}

The analysis of the data is grounded in Hymes' (1964, 71) "SPEAKING" framework to describe and interpret the different communication situations and speech events in which the act of naming took place. This framework is a useful heuristic that Saville-Troike $(2003,110-24)$ identifies as consisting of the components of communication. These components are broken down into genre, topic, purpose, setting, key, participants, message form, message content, act sequence, rules for interaction, and the norms of interpretation (110-111). This model provided a starting point from which to focus on specific acts of naming and uncover the distinct meaning behind such acts. From here, an iterative analysis, as outlined by Tracy $(2013,184)$, allowed me to group my descriptive (or first-level) identifications and meanings into three key categories, or second-level meanings, and then to postulate an even more abstract concept that these categories could be part of.

\section{FINDINGS \& ANALYSIS}

Through the data collection process, participants' meanings and uses of naming allowed me to understand how naming was involved in defining and reinforcing solidarity between speakers. The three major categorical meanings behind naming in interpersonal conversation within the university community were revealed to be: (1) getting another's attention in a dramatic way or with a specific purpose, (2) accentuating a joke, and (3) bringing speakers closer together.

Attention-getting

Regarding getting an individual's attention through naming, I looked beyond the obvious use of a name when calling to an individual, and moved towards use of names in circumstances where "getting attention" in the literal sense is not necessary. I noticed that naming was employed to reinforce a point or add emphasis or drama to the topic of conversation. Reinforcement 
of a point includes reprimanding or informing, especially when subtlety is of key importance.

For example, when out with friends, an insulting comment about a neighboring group was made in French. The speaker said, "nous sommes un petit comité," (we are a small group) sarcastically referring to the unfriendly nature of the other individuals; they were not open to having a conversation with our group. When one of the members of our group (who does not speak French, participant L) pushed to understand what was being said and would not let it go, another group member, who picked up on what was going on, turned to her and said her name in a serious, reprimanding manner along with a wide-eyed, meaningful look. This short act helped L understand that she needed to let the comment go, and she did. In this case, it wasn't necessary to specifically get L's attention, but instead to subtly draw her attention to a social cue that was being missed and to increase shared understanding within the group.

The use of naming can also be found in instances that do not involve a reprimand but merely to serve to add a sense of drama to the interaction. This was seen most clearly during a dinner party I attended, consisting of six students from various cultural backgrounds. I helped serve the dinner by carving the chicken, and had some difficulties. I made a joke about giving one of the visitors an entire leg and thigh all together. While laughing, two of my friends tried to come to my rescue saying, "Claire, wait," and "Claire, let me help you." There was a sense of urgency in their tone, and they spoke rapidly, enhancing the drama of the moment, even though they weren't entirely serious. Participant $\mathrm{C}$ (one of the speakers) commented later that, "we use someone's name to get their attention, but then there's an exaggeration..." This indicates how getting someone's attention can go beyond the purely literal purpose and takes on a varied, and unique purpose, in this case, getting attention or increasing urgency, and adding drama which is then shared by the interlocutors.

\section{Accentuating a Joke}

Naming is also often used to accentuate a joke. In Trinidad, according to participant $\mathrm{C}$ (a native of that country) when interviewed, there is actually word for this practice, called pikong (or picong). It refers specifically to an exaggerated way of ridiculing someone in good fun, and always consists of the joke being preceded by the individual's name. This was seen often among various groups of college students and in many different social situations. One such interaction was observed between three students: an American male ( $\mathrm{J})$, one American female (P1) and one British female (P2).

$\mathrm{P} 1, \mathrm{P} 2$, and $\mathrm{J}$ were in front of the university chatting when I arrived. J was being asked for all the details from his weekend with his parents and was purposely taciturn and straightforward in his responses. The girls (P1, P2) began to jokingly accentuate the way they asked the questions by using a singsong tone of voice and repeatedly elongating J's name, taking turns asking him questions and teasing him.

P1: "Why don't you hang out with us, J? You should hang out with us more!"

J: "I don't know...?"

P2: [arm around J's shoulder] "It's because he's hanging out with his girlfriend!"

Me: "Oh, really?"

P1: [laughing] "No, no, but you do have a crush on someone, don't you J?"

J: [stepping back] "What? No!"

P2: [in mock serious tone] "There's no use denying it, J. We know aaaaall about it."

P1, P2: [laughter]

This interaction is typical between P1 and P2 with their friends. J, especially, is often the subject of much teasing, but it is known by all parties to be in good fun and not malicious in any way. P1 and P2 like him, and want to reinforce their closeness with him by joking with him about his life. P1 and P2 conveyed the joking nature of their questions by their sing-song tone and the repetitive format of each question, which included addressing J by his name in almost every speech act. There are other ways to convey joking, perhaps by laughing or addressing him in a more outrageous tone, but the purpose of this act was to increase closeness between the participants through teasing and the use of a more intimate term of address, and to make the closeness more natural by using his name to excess and incorporating it into the joke.

Teasing has been uncovered to be a discursive tool, which in its ambiguous nature allows for both humorous and non-humorous goals to be achieved. Dynell (2011) asserts that teasing is most often used in situations in order to mitigate "intentionally produced aggressive acts" (230), but it is also worth noting that this same ambiguous act can carry out a more connective func- 
tion, modifying attempts at establishing greater relational intimacy between interlocutors as seen above through an ambiguity that creates a more casual context.

Bringing People Together

Lastly, naming was often found as a conversational tool to maintain a connection between two speakers or to bring two members of a conversation closer together. As participant $\mathrm{H}$ commented when interviewed, using names draws people in and brings people closer together, "it is acknowledging their person, their humanity, like their unique personhood." This act of 'bringing together' can be achieved especially by demonstration of solidarity and support through the use of naming.

Bringing people together was seen most often when individuals were sharing something or saving face. During the dinner party mentioned above, after the "chicken incident," participant $\mathrm{R}$ addressed me with the aim to reassure my pride that $\mathrm{I}$ was doing an adequate job serving dinner. She addressed me, saying, "Don't worry if the chicken is shredded, I'll eat it anyway. Claire, just blame it on the knife." The use of my name reflected a desire to reinforce the fact that by addressing me, she was supporting me and saving face, which established a greater connection between us in the ongoing conversation. Another incident occurred later when $\mathrm{R}$ received her plate of chicken and found a bone on the plate not connected to her meat. She was surprised and laughed about it, and $\mathrm{H}$ turned to her and held up her own bone, saying, "You and me, R." Here, $\mathrm{H}$ was reinforcing a connection to $\mathrm{R}$ within the conversational group by using her name to share the fact that they both had a useless bone on their plate and something to laugh about together.

These three meanings can be identified as interactional methods of establishing and maintaining relationships with others. The participants defined naming as something they used to delineate relationships in general terms, when their attention was brought to it. As stated by participant A, when discussing when and why she uses her sister's boyfriend's name frequently in conversation, "I use names more when I have a closer relationship with the person." The use of names reflects the status of the relationship between speaker and addressee. Depending on the circumstance, usage also increases solidarity and intimacy between speakers.

\section{CONCLUSION}

While many of the previous studies on terms of address focused on how address choice reflects and constructs identity, this study helped to uncover the relational and social constructive functions of naming in this particular speech community, following what was initiated by Norrby and Warren $(2012,29)$ regarding terms of address and social construction. Here it has been shown that naming functions to get attention in a dramatic way, to soften the blow or increase intimacy through a joke, or to bring people together, especially in terms of reassurance.

All three of the meanings uncovered connect to solidarity, support, and intimacy or closeness as key factors informing address term choice in the majority of naming instances in this speech community. This concept of solidarity is also analyzed in various other studies on naming. For example, Weizman (2008, 117) interpreted that in news interviews in Israel, first names were used to appeal to the positive face (or need to be liked) of the interlocutor, thereby increasing solidarity within the context of the speech event. Weizman also noticed that the use of names could go the other way, serving to present a challenge to the respondent. While my research did not focus names used specifi- 
cally as a challenge, the use of names in attention-getting often served to mitigate or accentuate a reprimand (which functions as a kind of challenge to the face of the reprimanded party). Perhaps if the speech community were one that included a greater variety of speech events, especially ones that take place in "challenge environments" (Weizman 2008, 116) the use of names as threats or challenges would become apparent.

Through this study we see that naming serves to enforce a shared understanding of a communication situation, and this shared understanding then leads to solidarity between participants. This sense of connection and even intimacy carried through naming connects to its use in jokes as well, because by acknowledging a person directly by their name while teasing them makes the joke less "mean," it "softens the blow," or reassures the other person that what is being said really is a joke, increasing the closeness of the interlocutors. The act of naming also adds a greater feeling of support to an interaction, contributing to an increase in closeness between interlocutors due to the sympathetic nature of the speech act. All of these functions achieve an increase or maintenance of closeness and solidarity between the speaker and the "named" party within the context of the speech community.

Further research on different speech communities would be useful to establish cross-cultural contrasts and thus identify if there are any more universal aspects of this practice. There are other uses of naming that, although they did not appear in my data, could have appeared in different speech communities. As mentioned, the use of naming as a challenging or threatening act, which I did not observe during my research, might have occurred in a different context (perhaps a workplace) and perhaps related to Aghbari's $(2010,347)$ observation of the use of naming as an insult. Additionally, research in other contexts and with different theoretical approaches would be beneficial to better understand what naming means in interpersonal interactions and possibly uncover alternative answers to solidarity as a major impetus behind naming.

Through my research, I found that naming is often used as a practice that "unites" people in terms of solidarity or intimacy, but through informal observation and intuition, I believe that naming can also be used as "separating" communicative practice, by challenging or threatening others, and further research to better understand this would enrich the observations outlined here. 


\section{REFERENCES}

Aghbari, Khalsa A. 2010. "Derogatory Forms of Personal Names in Omani Arabic." Anthropological Linguistics 52(3/ 4), 344-357. JSTOR Arts and Sciences VI (accessed April 30. 2014).

Brown, Roger, and Albert Gilman. 1960. The Pronouns of Power and Solidarity: Style in Language. Edited by T. A. Sebeok. Cambridge, MA: MIT.

Dynell, Marta. 2011. “Joker in the pack: Towards determining the status of humorous framing in conversations." In The Pragmatics of Humor Across Discourse Domains, edited by Marta Dynell, 217-241. Philadelphia: John Benjamins Pubishing Company.

Hymes, Dell. 1964. The Ethnography of Communication. Edited by J. J. Gumperz \& D. Hymes. Washington, DC: American Anthropological Association.

Kiesling, Scott F. 2004. "Dude." American Speech 79(3), 281-305.

Norrby, Catrin, and Jane Warren. 2012. "Address Practices and Social Relationships in European Languages." Language \& Linguistics Compass 6(4), 225-235. Academic Search Complete, EBSCOhost (accessed April 30, 2014).

Rendle-Short, Johanna. 2009. "The Address Term Mate in Australia: Is It Still a Masculine Term." Australian Journal of Linguistics 29(2), 245-268. http://www.academia.edu/6136014/ The_Address_Term_Mate_in_Australian_English_Is_it_Still_a_Masculine_Term

Saville-Troike, Muriel. 2003. The Ethnography of Communication, 3rd ed. Malden, MA: Blackwell Publishing.

Takiff, Hilary A, Diana T. Sanchez and Tracie L. Stewart. 2001. “What's in a Name? The Status Implications of Students'Terms of Address for Male and Female Professors." Psychology of Women Quarterly 25: 134-144.

Tracy, Sarah J. 2013. Qualitative Research Methods: Collecting Evidence, Crafting Analysis, Communicating Impact. Malden, MA: Wiley-Blackwell.

Villanueva, Margaret. 1995. “Gendered Namings and the Ironies of Fieldwork: Notes from Mexico's Gulf Coast." Women \& Language 18(1), 10-15. Academic Search Complete, EBSCOhost (accessed April 30, 2014).

Weizman, Elda. 2008. "Framing challenge through terms of address." Positioning in Media Dialogue: Negotiating roles in the news interview, 116-137. Philadelphia: John Benjamins Publishing Company.

Winchatz, Michaela R. 2001. "Social meanings in German interactions: An ethnographic analysis of the second-person pronoun Sie." Research on Language and Social Interaction 34(3), 337-369.

This work is licensed under a Creative Commons AttributionNonCommercialNoDerivs 3.0 Unported License. 